\title{
Rapid Shallow Breathing Index Survey, a Predictor of non-Invasive Ventilation Necessity in Patients With Chronic Obstructive Pulmonary Disease Exacerbation: An Analytical Descriptive Prospective Study
}

\author{
Hassan Soleimanpour ${ }^{1, *}$; Ali Taghizadieh ${ }^{2}$; Rasoul Salimi ${ }^{3}$; Samad EJ Golzari ${ }^{4}$; Ata \\ Mahmoodpoor ${ }^{5}$; Saeid Safari ${ }^{6}$; Robab Mehdizadeh Esfanjani ${ }^{7}$; Yaghoub Heshmat ${ }^{1}$ \\ ${ }^{1}$ Cardiovascular Research Center, Tabriz University of Medical Sciences, Tabriz, IR Iran \\ ${ }_{3}^{2}$ Tuberculosis and Lung Disease Research Center, Tabriz University of Medical Sciences, Tabriz, IR Iran \\ ${ }^{3}$ Students' Research Committee, Tabriz University of Medical Sciences, Tabriz, IR Iran \\ ${ }_{5}^{4}$ Medical Philosophy and History Research Center, Tabriz University of Medical Sciences, Tabriz, IR Iran \\ ${ }^{5}$ Anesthesiology and Critical Care Department, Tabriz University of Medical Sciences, Tabriz, IR Iran \\ 6 Anesthesiogy and Critical Cares \\ 7 Aneurosciences Research Center, Tabriz University of Medical Sciences, Tabriz, IR Iran \\ ${ }^{*}$ Corresponding Author: Hassan Soleimanpour, Cardiovascular Research Center, Tabriz University of Medical Sciences, Tabriz, IR Iran. Tel: +98-9141164134, Fax: +98-4113352078, E-mail: \\ soleimanpourh@tbzmed.ac.ir
}

Received: July 1, 2013; Revised: December 19, 2013; Accepted: January 20, 2014

\begin{abstract}
Background: Patients with Chronic Obstructive Pulmonary Disease(COPD) are susceptible to respiratory failure which would ultimately lead to their hospitalization. Need to Non-Invasive Ventilation (NIV) is considered as the choice respiratory support in acute respiratory failure and is associated with a beneficial role in patients with COPD exacerbation. Hence, determining patients that would benefit NIV could be of great assistance.

Objectives: We aimed at evaluating the use of Rapid Shallow Breathing Index (a ratio determined by the frequency (f)divided by the tidal volume (VT)) in NIV requirement in COPD patients.

Patients and Methods: In a prospective descriptive study, ninety eight patients over 40 years old with documented COPD exacerbation who were referred to emergency department of Imam Reza hospital, Tabriz, Iran were studied. Rapid Shallow Breathing Index (RSBI), ABG parameters and APACHE II scoring were measured in each patient. Quantitative data were analyzed by Student's t-test and One-way ANOVA and qualitative data were analyzed using chi square (X2). Findings were analyzed with SPSS software version 16.

Results: Patients requiring NIV included $43.9 \%$ of all studied patients. RSBI and APACHE II score with sensitivity of $94.8 \%$, (cut off point $=$ 110 ) and $72 \%$ (cut off point $=14$ ) respectively, had high diagnostic sensitivity and also the ability to predict patients requiring NIV. None of ABG parameters solely played a significant role in determining patients requiring NIV.

Conclusions: RSBI and APACHE II score in patients with COPD exacerbation are of the ability to predict NIV requirement, as a predicting factor of Non-Invasive Ventilation requirement.
\end{abstract}

Keywords: Noninvasive Ventilation; Blood; APACHE II

\section{Background}

COPD is characterized by an airflow limitation which is not fully reversible (1). At the moment, COPD is the fourth leading cause of morbidity and mortality throughout the world and is predicted to be known as the fifth cause of disability by $2020(2,3)$. Patients with COPD are susceptible to respiratory failure which would ultimately lead to their hospitalization.

One third to one fifth of the hospitalized patients suffering from secondary acute hypercapnic respiratory failure due to COPD exacerbation would expire despite being mechanically ventilated (4-8). Conventional treat- ments (bronchodilators, corticosteroids, antibiotics, and controlled oxygen) are mostly based on providing constant and sufficient oxygenation and treating the cause of disease exacerbation as well. However, the process of intubation and ventilation support in these patients is associated with an increased rate of complications and it would be difficult to wean these patients from ventilator $(9,10)$. Considering the complications associated with mechanical ventilation in patients with acute respiratory failure or COPD, researches have shown that Non-Invasive ventilation (NIV) could aid ventilation by reducing respiratory work; therefore reducing intubation, morbidity

Implication for health policy/practice/research/medical education:

The current descriptive-prospective study highlights the importance of RSBI [a ratio determined by the frequency (f) divided by tidal volume (VT)] and APACHE score in predicting non-invasive ventilation requirement in patients with COPD exacerbation. Despite being a painful and costly approach compared to RSBI which is an easy and non-invasive approach, ABG is routinely used to evaluate non-invasive requirement in these patients. In the present study, we demonstrated that RSBI could replace ABG as a reliable predicting factor for non-invasive ventilation requirement in patients with COPD exacerbation.

Copyright (c) 2014, Iranian Red Crescent Medical Journal; Published by Kowsar Corp. This is an open-access article distributed under the terms of the Creative Commons Attribution License, which permits unrestricted use, distribution, and reproduction in any medium, provided the original work is properly cited. 
and mortality rates in these patients $(11,12)$. To determine indications of requiring NIV in patients suffering respiratory failure, available guidelines are based on ABG findings in these patients which eventually would expose them to an invasive procedure; therefore, providing a non-invasive predictive factor necessitating NIV could be of great importance. Few studies have compared proper non-invasive indices predicting NIV requirement in patients with COPD. The rapid shallow breathing index (RSBI), being first introduced by Yang and Tobin in 1991, is a ratio determined by the frequency (f) divided by the tidal volume (VT). Healthcare professionals have been using this ratio successfully in most mechanical ventilation weaning protocols; as RSBI $<105$ is considered as a criterion for weaning to extubation (13).

\section{Objectives}

In this research, we hypothesized using Rapid Shallow Breathing Index (RSBI) conversely as a predictor of NIV requirement in patients with documented COPD exacerbation.

\section{Methods and Materials}

This descriptive-prospective study was carried out in emergency ward of Imam Reza Hospital, Tabriz, Iran (14). Imam Reza hospital is a general and public 300-bed educational referral hospital with 24 in-patient wards. This study was approved by the Ethics Committee of "Tabriz University of Medical Sciences" and registered under the Code Number 883. However, all aspects of the present study plan were explained to patients and then we obtained their written consent, including consent to participate in the study and consent to publish, where appropriate. Regarding the sample size evaluation, as we could not find any similar study in the literature review, we performed the study in a 6-month period (2011 March to 2011 August) and included all COPD patients who had the inclusion criteria in this period. Patient collection was performed from 8 a.m. until 4 p.m. seven days a week while no sample collection was performed in the evening or night shifts. The inclusion criteria were all the patients over 40 years old, COPD Exacerbation, History of smoking at least twenty pack per year.

Note: Smoking contributes to the incidence of COPD immensely ( $90 \%$ of the cases with COPD are caused by smoking); however COPD is rare before the age of 40 and many years are required for smoking to decrease FEV1 rapidly leading to COPD and in patients younger than 40 with COPD signs, other diagnoses should also be born in mind. Therefore, in the current study only were COPD patients older than 40 included (15). The exclusion criteria: Respiratory arrest, cardiovascular instability, lack of patient cooperation, upper airway obstruction, possibility of increased aspiration risk, morbid obesity, increase in secretions, recent facial trauma or gastroesophageal surgery, impaired mask fixation, nasopharyngeal abnor- malities, craniofacial trauma, lack of patient consent. For ABG analysis RAPID Point 340/350 Blood Gas Systems (Siemens, Germany) and for pulse oximetry, Alborz B7 (Saadat, Iran) were used. All instruments were calibrated prior to use. To determine the need for NIV, in all patients, ABG and simultaneous RSBI were measured using ventilator model "Vector ST40" with BLPAP mode EPAP $=5 \mathrm{~cm}$

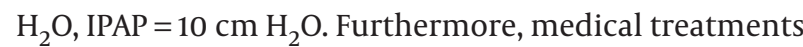
(intravenous corticosteroid, salbutamol spray, atrovent spray, antibiotics, and oxygen therapy) were administered. Duration and method of oxygen therapy was as following for all patients.

Indications for commencement of non-invasive ventilation (NIV) included exacerbation of COPD with $\mathrm{PH}<7.35$ and $\mathrm{PaCO}_{2}>45 \mathrm{mmHg}$ or $\mathrm{PaO}_{2}<60 \mathrm{mmHg}\left(\mathrm{SpO}_{2}<90 \%\right)$ despite receiving $\mathrm{Max}_{\mathrm{FIO}}$ of $60 \%$. Titrated Oxygen therapy was initiated using Venturi mask at $\mathrm{FIO}_{2}$ of $24 \%$ to $60 \%$ for all patients based on pulse oximetry every 20 minutes to achieve $\mathrm{SpO}_{2}>90 \%$ (for maximum of two hours). In case of not achieving $\mathrm{SPO}_{2}>90 \%$ despite receiving $\mathrm{FIO}_{2}$ $>60 \%$, patients underwent NIV. After administering the above-mentioned treatments and oxygen therapy for two hours, required variables on admission, one hour and two hours after treatment were measured; ultimately patients were divided into two groups of requiring noninvasive ventilation (group I) and not requiring non-invasive ventilation (group II). Patients requiring non-invasive ventilation were hospitalized after consulting with a pulmonologist and patients who were not hospitalized or did not require non-invasive ventilation, depending on clinical condition, were discharged from emergency service or referred to pulmonary subspecialty clinic. Findings obtained from the measured RSBI and ABG of the patients in three stages and also APACHE II score for two groups were analyzed using SPSS16 software. For statistical study, descriptive statistical analysis was used (frequency, percentage, mean \pm standard deviation). Normal data distribution was evaluated by Kolmogorov-Smirnov test. Quantitative data, if required, were analyzed by Student's t-test or Mann-Whithney U test, also Repeated Measurements Analysis and qualitative data were analyzed by Chi-square test $\left(\mathrm{X}^{2}\right)$. Logistic Regression tests were used for determining effective factors on patients requiring NIV. In addition, ROC was used to determine sensitivity of different variables in predicting NIV requirement. In this study, P value less than 0.05 was considered significant.

\section{Results}

In the present study, 98 patients including 64 males and 34 females were examined. The mean age of the patients was $68.43 \pm 10.29$ years with the median of 68.5 years. The youngest and the oldest patients were 42 and 89 years, respectively. The mean age of patients was $68.69 \pm 10.94$ and $68.23 \pm 9.84$ years in groups requiring NIV (group I) and not requiring NIV (group II), respectively. No significant difference was observed between both groups 
in this regard $(\mathrm{P}=0.82)$. Furthermore, there was no significant difference between two groups considering sex distribution $(P=0.83)$. Among vital signs measured in three stages (on admission, an hour and two hours after admission), respiration rate and heart rate in each three stage were significantly high in group requiring NIV. Table 1 illustrates the findings of ABG analysis between two groups. As it can be seen, findings of $A B G$ in patients not requiring NIV are considerably better than group I. Table 2 presents respiratory findings in two groups. As it can be seen, respiratory findings in patients not requiring NIV are also significantly better than group I.

None of the variables resulted from ABG analysis based on Logistic regression model revealed any significant role as predicting factor of invasive ventilation necessity in patients with COPD exacerbation. Using Logistic Regression statistical tests to evaluate the predictive value of ABG, Tidal volume (TV), Minute ventilation (MV) and RSBI variables for non-invasive ventilation necessity in patients with COPD exacerbation revealed that RSBI prior to treatment and an hour and two hours subsequent to treatment, in addition to possessing high diagnostic sensitivity in patients requiring NIV, has a significant predictive ability on admission [Odd's ratio equal to (CI 1.04-1.09) 1.07 and P < 0.001], an hour [Odd's ratio equal (CI 1.05-1.1) 1.08 and $\mathrm{P}<0.001$ ] and two hours subsequent to treatment [Odd's ratio was (CI 1.09 - 1.27) 1.1 and $\mathrm{P}<0.001$ ] in patients requiring NIV. As at each measured stages (on admission, an hour and two hours subsequent to treatment) evaluated sensitivity ratios were $94.8 \%, 92.8 \%, 97.7 \%$ and specificity values were $94.8 \%, 92.8 \%$ and $97.7 \%$, respectively. Also Youden's index (J), defined by: J = maximum \{sensitivity (c) + specificity (c) -1 \} were $0.96,0.84$ and 0.94 , respectively and values for cutoff point were more or equal to 110, 105 and 107, respectively (Figure 1 ).

\begin{tabular}{|c|c|c|c|c|}
\hline & $\begin{array}{l}\text { Group I (Requiring } \\
\text { NIV) }\end{array}$ & $\begin{array}{l}\text { Group II (Not Requir- } \\
\text { ing NIV) }\end{array}$ & P value Within Group & $\begin{array}{l}\text { P value Between } \\
\text { Group }\end{array}$ \\
\hline PH at admission & $7.24 \pm 0.05$ & $7.34 \pm 0.05$ & $<0.0001$ & $<0.0001$ \\
\hline PH 60 minutes later & $7.26 \pm 0.04$ & $7.34 \pm 0.04$ & $<0.0001$ & $<0.0001$ \\
\hline PH 120 minutes later & $7.27 \pm 0.03$ & $7.36 \pm 0.02$ & $<0.0001$ & $<0.0001$ \\
\hline $\begin{array}{l}\mathrm{PaO}_{2} \text { at } \\
\text { admission(mmHg) }\end{array}$ & $43.86 \pm 6.37$ & $49.46 \pm 5.79$ & $<0.0001$ & $<0.0001$ \\
\hline $\begin{array}{l}\mathrm{PaO}_{2} 60 \text { minutes later } \\
(\mathrm{mmHg})\end{array}$ & $52.38 \pm 4.04$ & $55.02 \pm 4.78$ & $<0.0001$ & $<0.0001$ \\
\hline $\begin{array}{l}\mathrm{PaO}_{2} 120 \text { minutes } \\
\text { later }(\mathrm{mmHg})\end{array}$ & $55.72 \pm 3.51$ & $62.82 \pm 2.06$ & $<0.0001$ & $<0.0001$ \\
\hline $\begin{array}{l}\mathrm{PaCO}_{2} \text { at admission } \\
(\mathrm{mmHg})\end{array}$ & $62.73 \pm 15.27$ & $49.26 \pm 12.26$ & 0.009 & $<0.0001$ \\
\hline $\begin{array}{l}\mathrm{PaCO}_{2} 60 \text { minutes } \\
\text { later }(\mathrm{mmHg})\end{array}$ & $60.84 \pm 14.00$ & $45.76 \pm 12.05$ & 0.009 & $<0.0001$ \\
\hline $\begin{array}{l}\mathrm{PaCO}_{2} 120 \text { minutes } \\
\text { later }(\mathrm{mmHg})\end{array}$ & $58.99 \pm 11.18$ & $46.70 \pm 9.54$ & 0.009 & $<0.0001$ \\
\hline BE at admission & $-0.19 \pm 0.74$ & $0.69 \pm 0.54$ & 0.136 & 0.42 \\
\hline BE 60 minutes later & $-0.21 \pm 0.60$ & $-0.67 \pm 0.58$ & 0.136 & 0.42 \\
\hline BE 120 minutes later & $-0.24 \pm 0.53$ & $0.90 \pm 0.44$ & 0.136 & 0.42 \\
\hline $\begin{array}{l}\mathrm{HCO}_{3} \text { at admission } \\
(\mathrm{mEq} / \mathrm{L})\end{array}$ & $28.06 \pm 5.12$ & $26.20 \pm 4.95$ & 0.065 & 0.007 \\
\hline $\begin{array}{l}\mathrm{HCO}_{3} 60 \text { minutes } \\
\text { later }(\mathrm{mEq} / \mathrm{L})\end{array}$ & $27.36 \pm 4.37$ & $25.39 \pm 4.54$ & 0.065 & 0.007 \\
\hline $\begin{array}{l}\mathrm{HCO}_{3} 120 \text { minutes } \\
\text { later }(\mathrm{mEq} / \mathrm{L})\end{array}$ & $27.73 \pm 4.67$ & $24.53 \pm 5.35$ & 0.065 & 0.007 \\
\hline $\mathrm{SpO}_{2}$ at admission (\%) & $62.48 \pm 9.68$ & $70.29 \pm 12.82$ & $<0.0001$ & $<0.0001$ \\
\hline $\begin{array}{l}\mathrm{SpO}_{2} \\
(\%)\end{array}$ & $77.09 \pm 6.69$ & $82.78 \pm 6.25$ & $<0.0001$ & $<0.0001$ \\
\hline $\begin{array}{l}\mathrm{SpO}_{2} 120 \text { minutes } \\
\text { later }(\%)\end{array}$ & $84.10 \pm 5.06$ & $91.47 \pm 1.47$ & $<0.0001$ & $<0.0001$ \\
\hline
\end{tabular}

\footnotetext{
a Abbreviations: NIV: Non-Invasive Ventilation
} 
Soleimanpour Het al.

\begin{tabular}{|c|c|c|c|c|}
\hline & $\begin{array}{l}\text { Group I (Requiring } \\
\text { NIV) }\end{array}$ & $\begin{array}{l}\text { Group II (Not Requir- } \\
\text { ing NIV) }\end{array}$ & P value Within Group & $\begin{array}{l}\text { Pvalue Between } \\
\text { Group }\end{array}$ \\
\hline TV at admission & - & - & $<0.0001$ & $<0.0001$ \\
\hline Percentile 25 & 176 & 247 & - & - \\
\hline Percentile 50 & 202 & 277 & - & - \\
\hline Percentile 75 & 221 & 312 & - & - \\
\hline TV 60 minutes later & - & - & $<0.0001$ & $<0.0001$ \\
\hline Percentile 25 & 185 & 257 & - & - \\
\hline Percentile 50 & 204 & 288 & - & - \\
\hline Percentile 75 & 228 & 338 & - & - \\
\hline TV 120 minutes later & - & - & $<0.0001$ & $<0.0001$ \\
\hline Percentile 25 & 188 & 261 & - & - \\
\hline Percentile 50 & 188 & 296 & - & - \\
\hline Percentile 75 & 231 & 351 & - & - \\
\hline RSBI at admission & - & - & $<0.0001$ & $<0.0001$ \\
\hline Percentile 25 & 132.1 & 63.1 & - & - \\
\hline Percentile 50 & 152.3 & 73 & - & - \\
\hline Percentile 75 & 186 & 96.1 & - & - \\
\hline RSBI 60 minutes later & - & - & $<0.0001$ & $<0.0001$ \\
\hline Percentile 25 & 114 & 67.3 & - & - \\
\hline Percentile 50 & 126.5 & 77.9 & - & - \\
\hline Percentile 75 & 145.8 & 89.4 & - & - \\
\hline RSBI 120 minutes later & - & - & $<0.0001$ & $<0.0001$ \\
\hline Percentile 25 & 106.3 & 56.7 & - & - \\
\hline Percentile 50 & 112.1 & 70.1 & - & - \\
\hline Percentile 75 & 121.3 & 80.7 & - & - \\
\hline MV at admission & - & - & 0.81 & 0.04 \\
\hline Percentile 25 & 4.44 & 5.54 & - & - \\
\hline Percentile 50 & 6.24 & 6.86 & - & - \\
\hline Percentile 75 & 7.39 & 7.8 & - & - \\
\hline MV 60 minutes later & - & - & 0.81 & 0.04 \\
\hline Percentile 25 & 4.35 & 5.45 & - & - \\
\hline Percentile 50 & 5.62 & 6.62 & - & - \\
\hline Percentile 75 & 6.66 & 7.5 & - & - \\
\hline MV120 minutes later & - & - & 0.81 & 0.04 \\
\hline Percentile 25 & 4.46 & 5.17 & - & - \\
\hline Percentile 50 & 5.42 & 6.21 & - & - \\
\hline Percentile 75 & 6.15 & 7.19 & - & - \\
\hline
\end{tabular}

\footnotetext{
a Abbreviations: NIV: Non-Invasive Ventilation; TV: Tidal Volume; RSBI: Rapid Shallow Breathing Index; MV: Minute ventilation
}

In the study in addition to RSBI, APACHE II score (with measured mean scores of $16.67 \pm 3.29$ and $14.12 \pm 3.12$ in groups I and II respectively) was of high sensitivity [Odd's ratio with (CI $1.5-1.1) 1.29$ and $\mathrm{P}=0.001$ ] with sensitivity of $72 \%$, specificity of $72 \%$ and cut of point of 14 . And based on Regression model, APACHE II score had a significant predicting role for non-invasive ventilation necessity in patients with COPD exacerbation (Figure $2)$. Eventually after two hours administration of oxygen, 43 patients ( $43.9 \%$ ) were placed in group requiring NIV and 55 patients (56.1\%) in group not requiring NIV. 


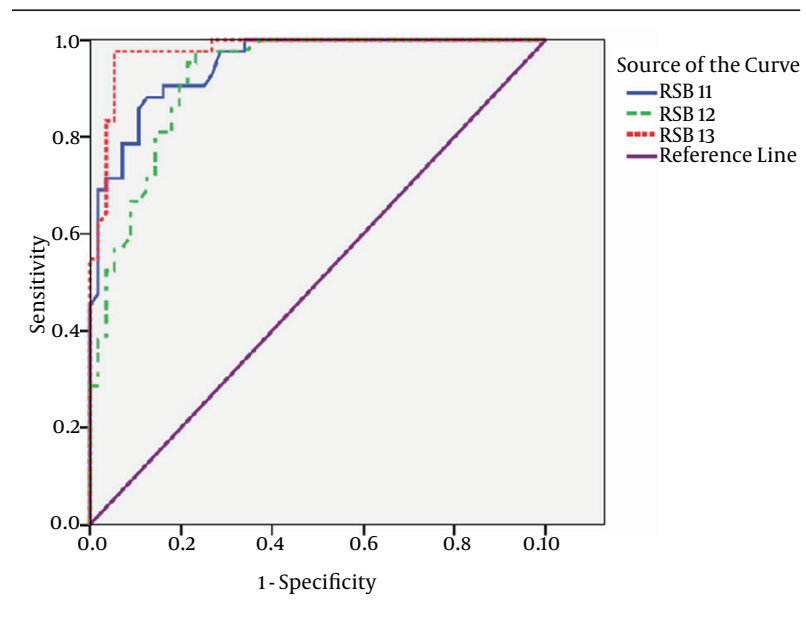

Figure 1. ROC Curve for RSBI Measurement at Three Stage of Measurement

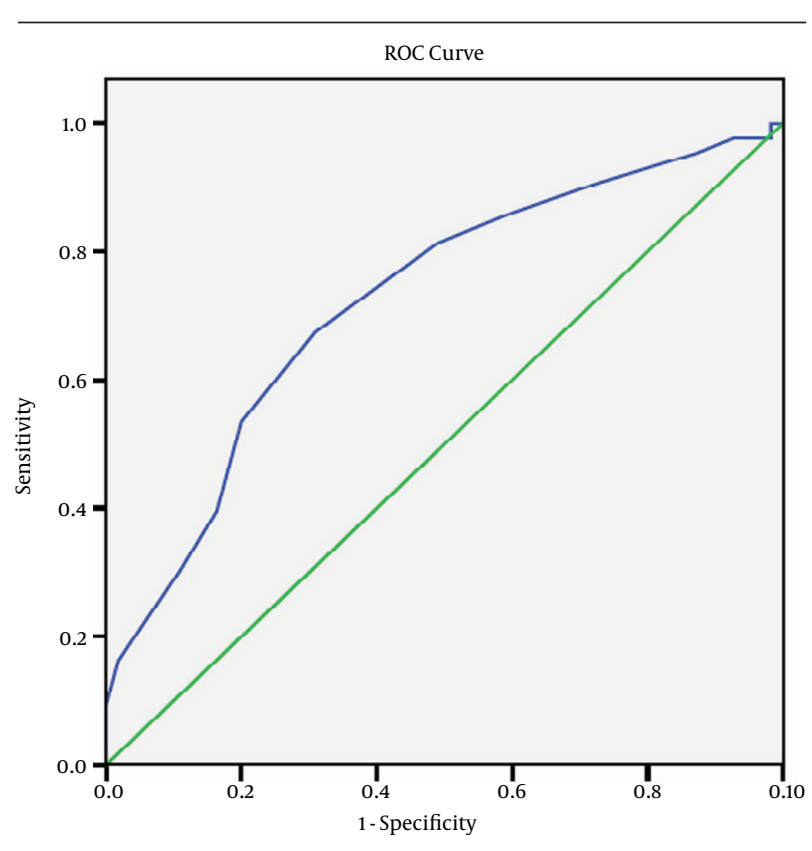

Figure 2. ROC Curve for APACHE II Scoring

\section{Discussion}

To determine indications of NIV, different criteria have been stated most of which necessitate ABG analysis for definite indication of NIV requirement (16). Indications of NIV commencement include: COPD exacerbation, moreover $\mathrm{PH}<7.32$ and $\mathrm{PaCO}_{2}>45 \mathrm{mmHg}$ or $\mathrm{PaO}_{2}<$ $60 \mathrm{mmHg}$ despite receiving oxygen with $\mathrm{Max} \mathrm{FIO}_{2}$ of $60 \%$ (12). Very few studies has been carried out to eliminate invasive interventions for determining NIV indication including Crawford's study in which different parameters have been studied for determining the index of NIV requirement such as: RSBI, PH, Lactate, MV, Carbon Dioxide production $\left(\mathrm{VCO}_{2}\right)$, End-Tidal $\mathrm{CO}_{2}$ (ETCO2), Air way dead space and APACHE II criterion. In this study using the Receiver Operating Characteristic (ROC) value revealed that RSBI more or equal to 120 was associated with the highest sensitivity and specificity for determining the need for non-invasive ventilation and it was consequently declared as a non-invasive index for evaluating the NIV requirement in patients with acute respiratory failure in emergency department (17). However, in the study of Lin et al. RSBI failed to be considered as a good predicting factor of successful non-invasive ventilation (NIV) intervention in patients with acute respiratory failure. In the study, it was stated that APACHE II score prior to treatment, PImax 30 minutes later, and RR 30 and 60 minutes later were all significantly lower in group not requiring NIV (18). Youshida et al. observed that patients in need of intubation had significantly higher APACHE II scores and lower arterial pH, as APACH II score higher than 17 and respiratory rate above 25 per minute after receiving NIV for an hour were introduced as independent determinants of requiring intubation (19). Our study, compared to other studies, is one of the few studies to have examined APACHE II score and various indices such as ABG and RSBI regarding their predictive ability for NIV requirement in patients with COPD exacerbation. Furthermore, more sample size of this study compared to Crawford's (98 to 61) and also following-up the predictive ability of RSBI in NIV requirement in the first two hours of treatment are considered as the advantages of this research. On the other hand, the sampling strategy and inability to generalized finding to the target population are considered as the limitations of the present study. In this research RSBI and APACHE II score in patients with COPD exacerbation revealed the ability to predict the need for NIV, as a predicting factor of non-invasive ventilation requirement. It is therefore recommended that APACHE II and RSBI factors be used as predicting factors in non-invasive ventilation requirement in patients with COPD exacerbation.

\section{Acknowledgements}

We thank Dr. Wilhelm Behringer, Professor of Emergency Medicine, Internist, Intensivist, Emergency Physician, Department of Emergency Medicine, Vienna General Hospital, Medical University Vienna. We have to express our deep gratitude to him for his comments on our paper. His input was instructive and helpful, and we greatly respect his guidance in scientific issues as well as in research ethics. The authors are grateful to all the health personnel and patients who participated in the study, in addition to the data collectors, supervisors and administrative staff of Emergency department of Imam Reza Hospital. Special thanks to Research Vice Chancellor Tabriz University of Medical Sciences for all the material and financial support in our study. "This article was written based on a dataset of specialty degree, registered in Tabriz University of Medical Sciences." 


\section{Authors' contributions}

Hassan Soleimanpour, Ali Taghizadieh, Samad EJ Golzari and Rasoul Salimi performed the clinical data collection, literature review, and drafting the manuscript. Ata Mahmoodpoor, Saeid Safari, Robab Mehdizadeh Esfanjani and Yaghoub Heshmat undertook the major parts of the study design and performed the statistical analysis. All of the authors were involved in either managing the patients or writing the manuscript. All authors read and approved the final manuscript.

\section{Funding Support}

This article was supported by Research Vice Chancellor of Tabriz University of Medical Sciences, Tabriz, Iran.

\section{Financial Disclosure}

The author declare that they have no competing interests and no financial disclosure.

\section{References}

1. Barnes PJ. Chronic obstructive pulmonary disease: important advances. Lancet Respir Med. 2013;1(1):e7-8.

2. Schroeder S. Smoking-related mortality in the United States. $N$ Engl J Med. 2013;368(18):1753-4.

3. Lopez AD, Murray CC. The global burden of disease, 1990-2020. Nat Med.1998;4(11):1241-3.

4. Mador MJ, Sethi S. Systemic inflammation in predicting COPD exacerbations. JAMA. 2013;309(22):2390-1.

5. Bott J, Carroll MP, Conway JH, Keilty SE, Ward EM, Brown AM, et al Randomised controlled trial of nasal ventilation in acute ventilatory failure due to chronic obstructive airways disease. Lancet. 1993;341(8860):1555-7.

6. Brochard L, Mancebo J, Wysocki M, Lofaso F, Conti G, Rauss A, et al. Noninvasive ventilation for acute exacerbations of chronic obstructive pulmonary disease. N Engl J Med. 1995;333(13):817-22.
7. Foglio C, Vitacca M, Quadri A, Scalvini S, Marangoni S, Ambrosino N. Acute exacerbations in severe COLD patients. Treatment using positive pressure ventilation by nasal mask. Chest. 1992;101(6):1533-8.

8. Jeffrey AA, Warren PM, Flenley DC. Acute hypercapnic respiratory failure in patients with chronic obstructive lung disease: risk factors and use of guidelines for management. Thorax. 1992;47(1):34-40.

9. Brochard L, Rauss A, Benito S, Conti G, Mancebo J, Rekik N, et al. Comparison of three methods of gradual withdrawal from ventilatory support during weaning from mechanical ventilation. Am J Respir Crit Care Med.1994;150(4):896-903.

10. Esteban A, Frutos F, Tobin MJ, Alia I, Solsona JF, Valverdu I, et al. A comparison of four methods of weaning patients from mechanical ventilation. Spanish Lung Failure Collaborative Group. N Engl J Med. 1995;332(6):345-50.

11. Mahmoodpoor A, Golzari SE. APRV Mode in Ventilator Induced Lung Injury (VILI). Advanc Biosci Clin Med. 2014;2(1).

12. Bolton R, Bleetman A. Non-invasive ventilation and continuous positive pressure ventilation in emergency departments: where are we now? Emerg Med J. 2008;25(4):190-4.

13. Yang KL, Tobin MJ. A prospective study of indexes predicting the outcome of trials of weaning from mechanical ventilation. $N$ Engl J Med.1991;324(21):1445-50.

14. Soleimanpour H, Gholipouri C, Salarilak S, Raoufi P, Vahidi RG, Rouhi AJ, et al. Emergency department patient satisfaction survey in Imam Reza Hospital, Tabriz, Iran. Int J Emerg Med. 2011;4:2.

15. Global Initiative for Chronic Obstructive Lung Disease. 2011. Available from: http://www.goldcopd.org/uploads/users/files/GOLD_ Report_2011_Feb21.pdf.

16. Antro C, Merico F, Urbino R, Gai V. Non-invasive ventilation as a first-line treatment for acute respiratory failure: "real life" experience in the emergency department. Emerg Med J. 2005;22(11):7727.

17. Crawford J, Otero R, Donnino M, Garcia J, Khazal R, Lenoir T Rapid shallow breathing index - a key predictor for noninvasive ventilation. J Crit Care. 2007;11(Suppl 2):169.

18. Lin MS, Guo HR, Huang MH, Chen CR, Wu CL. Predictors of successful noninvasive ventilation treatment for patients suffering acute respiratory failure. J Chin Med Assoc. 2008;71(8):392-8.

19. Yoshida Y, Takeda S, Akada S, Hongo T, Tanaka K, Sakamoto A. Factors predicting successful noninvasive ventilation in acute lung injury. J Anesth. 2008;22(3):201-6. 